\title{
Optic Tract
}

National Cancer Institute

\section{Source}

National Cancer Institute. Optic Tract. NCI Thesaurus. Code C33218.

A continuation of the optic nerves just dorsal to the optic chiasm, formed by temporal fibers of the ipsilateral optic nerve and nasal fibers of the contralateral optic nerve, that carries axons to nuclei within the thalamus and relays visual information to the primary visual cortex of the occipital lobe. 